Supporting Information

\title{
Resistive switching in organic memories with a spin coated metal oxide nanoparticle layer
}

\author{
Frank Verbakel, ${ }^{1,2}$ Stefan C.J. Meskers, ${ }^{1,2}$ Dago M. de Leeuw ${ }^{3}$ and René A.J. Janssen ${ }^{1,2}$
}

1) Molecular Materials and Nanosystems, Eindhoven University of Technology, P.O. Box 513, 5600 MB Eindhoven, The Netherlands

2) Dutch Polymer Institute (DPI), P.O. Box 902, 5600 AX Eindhoven, The Netherlands

3) Philips Research Laboratories, High Tech Campus 4 WAG 11, 5656 AE Eindhoven, Netherlands

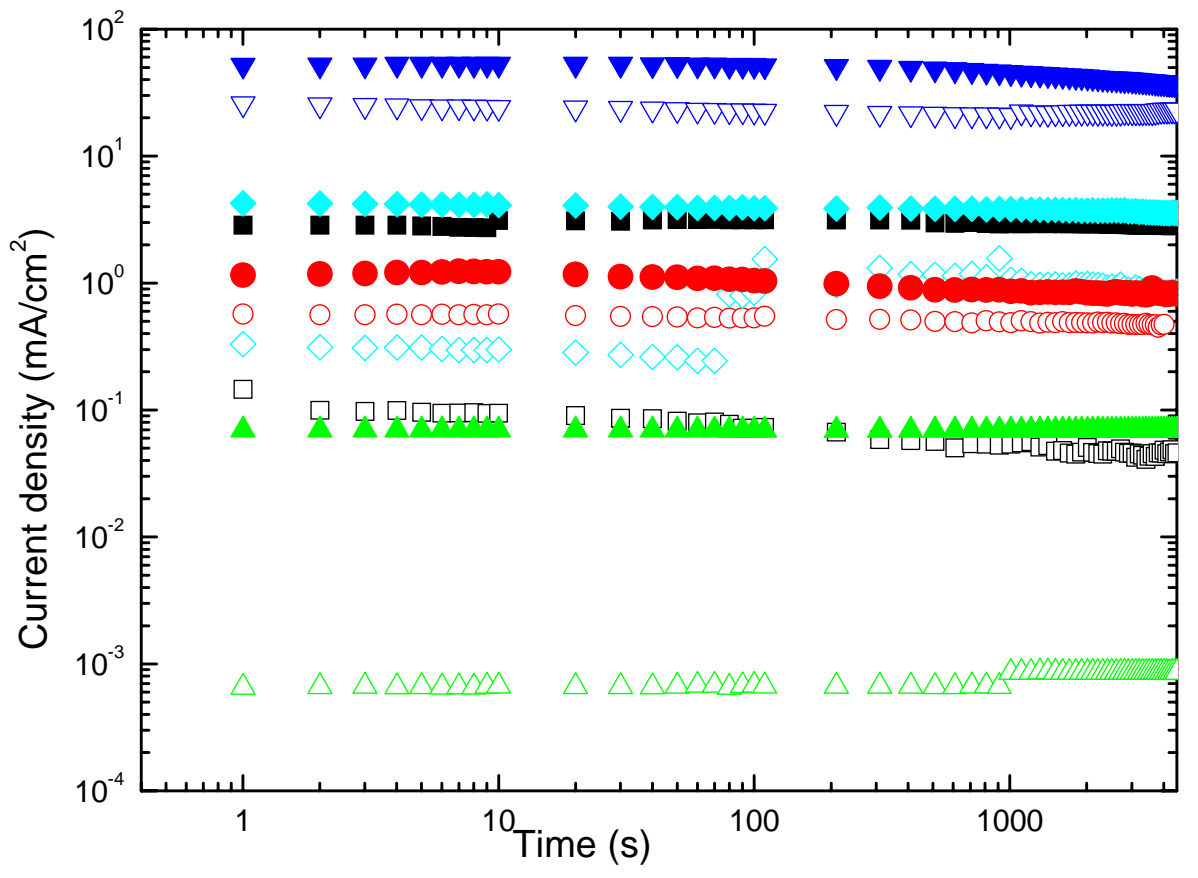

Figure S1: The low (closed symbols) and high (open symbols) resistance state versus

time for the devices with $\mathrm{Y}_{2} \mathrm{O}_{3}(\boldsymbol{\square}), \mathrm{TiO}_{2}(\boldsymbol{\nabla}), \mathrm{Al}_{2} \mathrm{O}_{3}(\Delta), \mathrm{ZrO}_{2}(\diamond), \mathrm{CeO}_{2}(\bullet)$. 


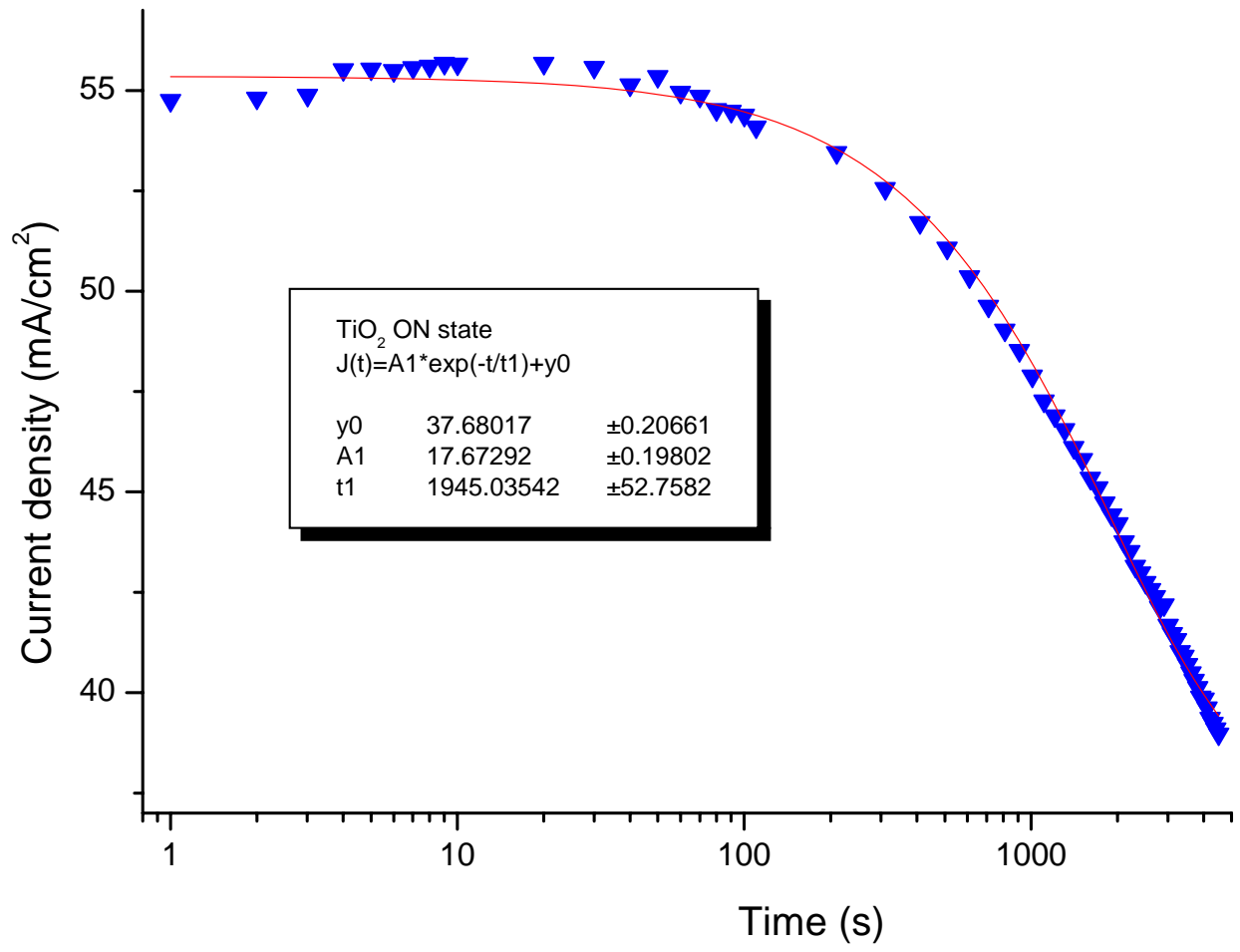

Figure S2: Time evolution in the low resistance state of the diode containing $\mathrm{TiO}_{2}$. The solid line represents a fit of an exponential decay to the data with characteristic time constant of $1.9 \times 10^{3} \mathrm{~s}$. 